\title{
The Complex Interactions Between Flowering Behavior and Fiber Quality in Hemp
}

\author{
Elma M. J. Salentijn, Jordi Petit and Luisa M. Trindade* \\ Plant Breeding, Wageningen University and Research, Wageningen, Netherlands
}

Hemp, Cannabis sativa L., is a sustainable multipurpose fiber crop with high nutrient and water use efficiency and with biomass of excellent quality for textile fibers and construction materials. The yield and quality of hemp biomass are largely determined by the genetic background of the hemp cultivar but are also strongly affected by environmental factors, such as temperature and photoperiod. Hemp is a facultative short-day plant, characterized

OPEN ACCESS

Edited by:

Donald Lawrence Smith, McGill University, Canada

Reviewed by: Kazuki Matsubara, Institute of Crop Science (NARO), Japan Vittoria Brambilla, University of Milan, Italy

${ }^{*}$ Correspondence:

Luisa M. Trindade

luisa.trindade@wur.n

Specialty section: This article was submitted to Crop and Product Physiology, a section of the journal

Frontiers in Plant Science

Received: 21 December 2018 Accepted: 25 April 2019

Published: 16 May 2019

Citation:

Salentijn EMJ, Petit J and Trindade LM (2019) The Complex Interactions Between Flowering Behavior and Fiber Quality in Hemp.

Front. Plant Sci. 10:614.

doi: 10.3389/fpls.2019.00614 by a strong adaptation to photoperiod and a great influence of environmental factors on important agronomic traits such as "flowering-time" and "sex determination." This sensitivity of hemp can cause a considerable degree of heterogeneity, leading to unforeseen yield reductions. Fiber quality for instance is influenced by the developmental stage of hemp at harvest. Also, male and female plants differ in stature and produce fibers with different properties and quality. Next to these causes, there is evidence for specific genotypic variation in fiber quality among hemp accessions. Before improved hemp cultivars can be developed, with specific flowering-times and fiber qualities, and adapted to different geographical regions, a better understanding of the molecular mechanisms controlling important phenological traits such as "flowering-time" and "sex determination" in relation to fiber quality in hemp is required. It is well known that genetic factors play a major role in the outcome of both phenological traits, but the major molecular factors involved in this mechanism are not characterized in hemp. Genome sequences and transcriptome data are available but their analysis mainly focused on the cannabinoid pathway for medical purposes. Herein, we review the current knowledge of phenotypic and genetic data available for "flowering-time," "sex determination," and "fiber quality" in short-day and dioecious crops, respectively, and compare them with the situation in hemp. A picture emerges for several controlling key genes, for which natural genetic variation may lead to desired flowering behavior, including examples of pleiotropic effects on yield quality and on carbon partitioning. Finally, we discuss the prospects for using this knowledge for the molecular breeding of this sustainable crop via a candidate gene approach.

Keywords: hemp, Cannabis sativa, short-day plant, flowering-time, phenology, sex determination, fiber development 


\section{INTRODUCTION}

Hemp (Cannabis sativa L.) is increasingly attractive as multipurpose crop for the sustainable production of fibers, oils, and cannabinoids (Van der Werf et al., 1996; Struik et al., 2000; Callaway, 2004; Karus and Vogt, 2004; Van der Werf, 2004; Barth and Carus, 2015; Andre et al., 2016, and references therein). As a quantitative short-day plant, photoperiod and temperature input are the key factors that determine the timing of flowering. Adaptation to the latitude of growth, characterized by a specific photoperiod and temperature regime, is very important for hemp production. Hemp flowering is inhibited in a regime of long-day photoperiod (LD) and is induced when a number of short-day photoperiods (SD) have passed (threshold $\sim 10-12 \mathrm{~h}$ of uninterrupted darkness; critical photoperiod $\sim 14-12 \mathrm{~h}$ of daylight). If the critical short-day is not reached within the growing season or if cultivars are very late flowering, the plants remain vegetative. Another important aspect of hemp phenology is its sexual dimorphism. Hemp is naturally dioecious, with the unisexual male and female flowers located on separate plants. Male and female plants do not flower and age simultaneously, with the male plants usually flower earlier (protandry) and age earlier. Since male flowers do not produce seed, a high frequency of male plants in the crop will reduce the seed yield. Male plants are also more susceptible to pests but have a finer fiber which is an advantage for application in textile manufacture. The development of stable monoecious cultivars (hermaphrodite plants, carrying male and female flowers on the same plant) is an important breeding goal. Compared to dioecious cultivars, the monoecious cultivars are more uniform in plant height, stem and seed production (Borthwick and Scully, 1954; Lisson et al., 2000a,b; Amaducci et al., 2008a,b, 2012; Salentijn et al., 2015; Small, 2015). However, while monoecious hemp is better for dual harvest of fiber and seed, it is considered that dioecious genotypes are superior for fiber production. There is evidence for genotypic variation in fiber quality, but due to the large variability in fiber characteristics created by environment and large influence of fiber extraction methods, the identification of varieties with specific fiber qualities is very difficult (Berenji et al., 2013; Amaducci et al., 2015).

Knowledge on the typical phenology of hemp is a prerequisite for successful hemp production and breeding for optimal combinations of flowering-time and fiber quality in a specific environment. Many aspects of hemp flowering are reviewed in detail by Hall et al. (2012). First of all, the development stage of hemp must be carefully monitored to determine the right moment for harvesting biomass for different products, and flowering-time is a main indicator for this. Around the onset of flowering, the flow of nutrients is shifting more to the development of flowers and seeds, and less to the development of stems, leaves, and roots, creating a change in carbon partitioning. Regarding fiber hemp, stem yield shows the highest increase before the onset of flowering and is positively correlated to the duration of the vegetative phase, and this is a reason why late-flowering cultivars with a prolonged vegetative phase produce the highest stem biomass (Höppner and
Menge-Hartmann, 2007; Faux et al., 2013; Hall et al., 2014; Tang et al., 2016). The time of maximal stem, bark, and fiber yield ("technical maturity") is reached at full (male) flowering (Mediavilla et al., 2001). Flowering time also marks the timepoint of secondary fiber formation, from the bottom-upward in the stem. At the flowering stage, the lignification process continues and intensifies (Keller et al., 2001; Liu et al., 2015), accompanied by a decrease in cellulose and pectin deposition with plant maturity (Liu et al., 2015). This situation results in a proportional decrease in the primary bast fiber layer and increase in secondary bast fiber fraction along the stem. Thus, the quality of the fibers is influenced by the developmental stage at harvest and it differs between different sections of the stem. Based on fiber quality measurements, the best quality fibers are obtained from the middle part of stems, harvested around flowering (Keller et al., 2001; Mediavilla et al., 2001; Li et al., 2013; Liu et al., 2018). In addition to this, the afterharvest process "field retting" is important for a good separation of bast fibers from the woody core (shives). This process also influences the fiber properties such as the color, cellulose content, and crystallinity of the fibers (Mazian et al., 2018). The decision of harvest date should therefore also be determined on the basis of the optimal weather conditions for field retting (not extremely wet or dry). For the dual production of seed and fiber, harvest takes place at seed maturity, resulting in an increased proportion of more lignified and shorter secondary fibers (Amaducci et al., 2015).

A great wish of breeders is to gain more control over the phenology and fiber quality of hemp in order to breed for varieties with specific combinations of flowering-time and seed and fiber qualities. Current hemp cultivars still contain levels of genotypic and phenotypic heterogeneity in sensitivity to photoperiod and stability of monoecy, of which the outcome in different environments is hard to predict. In this respect, the complex phenological traits "flowering-time" and "sex determination" are very important traits to consider in fiber hemp breeding. However, currently there is only little molecular information available for hemp. Here we evaluate current knowledge on genetic components for fiber quality, floweringtime control, and sex determination in hemp and in other crops, relevant to hemp. Candidate genes for phenology and fiber quality in hemp are proposed and the prospects for using this knowledge for hemp breeding are discussed.

\section{GENETIC FACTORS INVOLVED IN "FLOWERING-TIME": LEARNING FROM OTHER CROPS}

How are plants capable of sensing changes in their living environment, and how is the plant capable of responding to changing environments to ensure the most efficient timing of flowering?

Many studies, on multiple crops, have focused on the results of exhaustive analysis of the numerous genes involved in complex flowering-time gene networks in the model crops Arabidopsis thaliana (long-day plant) and rice (short-day plant), 
that are accessible via interactive databases (Bouché et al., 2016, http://www.flor-id.org, wikipathways: WP2312 (Arabidopsis) and WP2178 (rice)). From these studies, a complex picture emerged, whereby flowering is precisely controlled by cross-talk between multiple signaling pathways combining environmental and endogenous factors. This regulation network enables the plant to reproduce in changing environments.

The knowledge of flowering-time control is continuously expanding to other species, a broader range of floweringrelated traits, such as yield and stress components, and specific allelic functionalization of flowering-time regulatory genes (Jung et al., 2017). The main pathways regulating floweringtime are: (1) the photoperiodic pathway, induced by variation in day length, (2) the gibberellic acid (GA)-dependent pathway, (3) the autonomous pathway, governed by the plant's physiology status, independent of day length, (4) the vernalization and temperature pathway, induced by cold/ambient temperatures, (5) the aging pathway, induced by developmental factors that render the plant competent to flowering, and (6) the sugar pathway, in which the sugar status of the plant plays a role (e.g., Cho et al., 2018).

From studies in model crops, it is known that in the regulation of flowering-time, specific key genes are acting at distinct stages. The first stage is the perception and transduction of external signals; secondly, environmental and endogenous signals are transferred to special nodes in the signaling pathway; and thirdly, downstream "integrator genes" confer the capacity to flower to the meristems by the activation of floral meristem identity genes.

Hemp flowering is extremely sensitive to changes in photoperiod and temperature, and therefore the "photoperiodic pathway" and the "temperature pathway" seem to play prominent roles in regulating flowering-time in hemp.

The first stages in the "photoperiodic pathway" are the perception of light by photoreceptors (Smith, 2000; Jenkins, 2014; Christie et al., 2015; Galvão and Fankhauser, 2015; Xu et al., 2015; Kong and Okajima, 2016) and signal transduction to the central node of the "photoperiodic pathway" (the "GI-COFT" signaling cascade). The nuclear transcription factor CONSTANS (CO) acting in this node is essential for the induction of expression of FLOWERING LOCUS T (FT), coding for the mobile flower-promoting signal. $C O$ expression is temporally regulated by the "circadian clock" gene GIGANTEA $(G I)$, which has many other regulating functions in plant development, synchronizing genes in a 24 -h daily rhythm (e.g., Valverde et al., 2004 (CO); Wenkel et al., 2006 (CO); Mishra and Panigrahi, 2015 (GI)). The next steps are performed by downstream acting "integrator genes" such as FLOWERING LOCUS T (FT), FLOWERING LOCUS C (FLC), and SUPPRESSOR OF OVEREXPRESSION OF CONSTANS1 (SOC1) (for references, see Immink et al., 2012).

One of the most intriguing integrator genes involved in flowering is FLOWERING LOCUS T (FT or florigen; member of the CETS gene family). FT is the mobile flower-promoting signal that is transported over long distance from the leaf to meristems elsewhere in the plant to induce flowering (for references, see e.g., Notaguchi et al., 2008; Wigge, 2011).
It is now clear that specific members of the CETS gene family have antagonistic functions in maintaining vegetative growth (indeterminate growth) or promote flowering (determinate growth), indicating that flowering is regulated by balancing between family members (McGarry and Ayre, 2012; Lifschitz et al., 2014). FT originates from specific phloem companion cells of leaf veins (Chen et al., 2018). After loading to the phloem, FT is transported to meristems where it promotes the transition from vegetative growth to flowering, together with other "integrator genes," by regulating floral meristem identity genes which code for transcription factors such as LEAFY, APETALA1, AGAMOUS-LIKE 24, and FRUITFULL) (e.g., Lee and Lee, 2010).

An example of a successful approach to model flowering is the specific control of FT expression by transgenic ectopic overexpression or inactivation of FT. This approach was applied in angiosperm trees such as poplar, apple, citrus, and in a variety of woody and herbaceous species to induce precocious flowering (early flowering, shortening the juvenile stage), to facilitate an intermediate step that accelerates the breeding process (for ref, see Klocko et al., 2016). However, it has to be considered that in most crops, FT is encoded by small gene-families, with different functionalities and expression profiles among the members, within and among species. While some FT family members stimulate flowering, others may have the opposite function and inhibit flowering. Examples are reviewed by Wigge (2011), such as the case of sugar beet (B. vulgaris), where two FT-like genes are expressed, an activator and a repressor of flowering, and the case of tomato (L. esculentum) where one of the FT genes was not functioning on flowering but influenced leaf maturation, stem growth, and the formation of abscission zones. In such a situation, careful selection of specific candidate FT-loci is required. An example for the targeted inactivation of a specific FT gene, leading to delayed flowering, can be found in soybean. In soybean, ten FT homologs have been found and two of them are confirmed to control flowering ( GmFT2a and GmFT5a). Cai et al. (2018) used the CRISPR/Cas 9 system to specifically knock out GmFT2a in soybean, resulting in truncated nonfunctional proteins. The mutations were stably inherited to the next generations and several homozygous, transgene clean lines without signs of off-target activity were selected. These induced mutants displayed, as expected, late flowering under both SD and LD conditions. However, besides FT, also other genes in the flowering-time pathway could affect growth as was observed in a late-flowering, double loss-of-function mutant (soc1 fruitfull) that displayed a woody phenotype (Melzer et al., 2008).

FLOWERING LOCUS C (FLC) mainly integrates signals from ambient temperatures, vernalization and autonomous signals. In many plant species, a period of cold temperature is required in order to promote flowering in the following spring (vernalization). FLC is a floral repressor and, in Arabidopsis, a period of low temperature is needed to release this inhibition (Michaels and Amasino, 1999; Bouché et al., 2015; Cheng et al., 2017). FLC genes appeared to have been lost in several lineages of flowering plants (Ruelens et al., 2013). In hemp, the influence of temperature is especially important 
during the juvenile stage (basic vegetative stage). Hypothetically, it is possible that FLC-like genes, if expressed in hemp, are involved in timing the completion of the basic vegetative phase that requires a certain temperature input, before entering the photoperiod-sensitive phase. Initiation of hemp growth requires a base air temperature of around $1^{\circ} \mathrm{C}$, with an optimal temperature for growth of $29^{\circ} \mathrm{C}$ and a ceiling temperature $41^{\circ} \mathrm{C}$. For completion of the basic vegetative stage and floral initiation, temperature degree days in the range $306-636^{\circ} \mathrm{Cd}$ are required (Amaducci et al., 2008b, 2012).

The third main integrator gene SUPPRESSOR OF OVEREXPRESSION OF CONSTANS1 (SOC1) is a MADS-box transcription factor that, together with another transcription factor (AGL24), directly can activate the floral meristem identity gene $L E A F Y(L F Y)$. SOC1 acts in response to signals from multiple pathways; FLC (acting in the vernalization pathway) can bind to the promoters of SOC1 and FT to repress their expression (Li et al., 2008), SOC1 is indirectly regulated by CONSTANS (CO) via the levels of FT (photoperiod pathway), SOC1 expression is regulated via the "aging pathway" via a squamosa promoter-binding-like transcription factor (SPL9) and microRNA156 (see below), and SOC1 integrates the "gibberellic acid-dependent pathway" via a yet unclarified mechanism (for more information Lee and Lee, 2010; Immink et al., 2012; Hyun et al., 2016).

\section{NATURAL GENETIC VARIATION IN FLOWERING-TIME}

Hemp adapts strongly to the growing season of a given region and therefore it is important to grow the right cultivar for the desired yield, fiber, seed, or both. Also, the maturity of the crop at harvest has a strong influence on the fiber quality. As a general rule, late dioecious cultivars are good for fiber production and early cultivars better for seed production. For dual harvest of fiber and seeds, monoecious early- or mid-early flowering cultivars are advised (e.g., Faux et al., 2013; Amaducci et al., 2015; Tang et al., 2016). A range of cultivars is already available but there is still need for improvement, for instance by breeding varieties with specific fiber qualities, lower lignin content, lower pectin content, altered architecture or higher seed yield and quality, in combination with specific flowering-time (early-, mid-, late-flowering for specific environments) and sex determination (monoecious or dioecious) (Hall et al., 2012; Salentijn et al., 2015).

Early flowering, under noninductive (LD) conditions and reduced sensitivity to photoperiod is interesting for latitudinal adaptation of hemp and pivotal for reproductive success and good fiber and seed yields in Northern latitudes. Late flowering, with a prolonged vegetative stage is used for adaptation to low latitudes to obtain more yield.

In many crops, genetic variation in specific genes has been employed for the development of selection markers to speed up breeding of cultivars adapted to more extreme environments. Because flowering-time is a complex trait, characterization of flowering-time pathways and the specific natural allelic variation underlying genetic loci correlated to quantitative traits (QTLs) for flowering-time, the development of molecular markers for flowering behavior in hemp is needed. If we consider short-day crops like hemp, examples for the molecular control of floweringtime can be found in the monocot rice (Oryza sativa) and the dicot legume soybean (Glycine max (L.) Merr.).

In the short-day plant rice, natural variation in FT homologs is a characteristic for more day-neutral flowering. The main FT homolog in rice, Heading date $3 a$ (Hd3A)(Kojima et al., 2002), is upregulated in SD photoperiods and inhibited in LD, to allow flowering only in a SD regime and the central regulation node of flowering Arabidopsis (GI-CO-FT) is conserved in rice (OsGI-Hd1-Hd3a). Hd3a and its close homolog RICE FLOWERING LOCUS T 1 (RFT1) are essential for flowering under SD conditions (Komiya et al., 2008). In specific rice cultivars that were selected for early flowering in LD conditions, RFT1 is the major floral activator under LD conditions (Komiya et al., 2009). A rice ortholog of AtSOC1, OsMADS50 (Ryu et al., 2009) and Ehd1 (Doi et al., 2004) are positive regulators of RFT1 while Hd1 (Hayama et al., 2003), phyB (Dehesh et al., 1991), Ghd7 (Xue et al., 2008), Ghd8, and PRR37 (Yano et al., 2001) delay flowering under long-day conditions resulting in increased plant height, grain number per panicle, and grain yields (for references, see Komiya et al., 2009; Zhang et al., 2015; Hill and Li, 2016). Combinations of functional and nonfunctional alleles of these floral suppressors contribute to early flowering in LD and adaptation of rice to specific climates (Xue et al., 2008; Zhang et al., 2015).

In soybean, several natural variants controlling flowering and seed maturity time have been used in breeding for adaptation to the more Northern regions with longer periods of LD. These are mainly variants in the $E$ genes (E1 to E10), the juvenile (J) gene, and FT genes (GmFT2a, GmFT5a and FT4). The E1 gene (which is a legume-specific transcription factor) (Xia et al., 2012) and the FT4 gene (Samanfar et al., 2017) both act as floral repressors by downregulating GmFT2a and GmFT5a in LD conditions. E2 is an ortholog of GIGANTEA (Watanabe et al., 2011), whereas E3 and E4 encode phytochrome A genes (respectively GmPhya3 and GmPhya2)(Liu et al. (2008); Watanabe et al. (2009)) that integrate red to far-red ratios. The genes underlying loci $E 5$ to $E 8$ have not been identified yet, E9 is GmFT2a (Zhao et al., 2016), and FT4 is a candidate gene for the E10 locus (Samanfar et al., 2017). Plants carrying loss-of-function alleles for E1 to E4 lead to photoperiod insensitivity by allowing higher expression levels of the FT genes and promoting flowering under long-day conditions (for more references, see Zhai et al., 2015; Zhao et al., 2016; Copley et al., 2018).

\section{TRANSITION TO THE REPRODUCTIVE STAGE AND BAST FIBER QUALITY OF HEMP}

Transition to the adult, reproductive phase is an important moment. Around the onset of flowering, nutrient flow and carbon partitioning is shifted to the development of flowers and seeds, and less to the development of stems, leaves, and roots. 
In hemp, the transition from the vegetative to the adult phase can be recognized by a change in the leaf arrangement from opposite to alternate, the formation of inflorescences (Hall et al., 2012), a reduction in stem growth (Faux et al., 2013; Tang et al., 2016), and formation of secondary more lignified bast fibers from the bottom-upward in the stem (Keller et al., 2001; Mediavilla et al., 2001; Li et al., 2013; Liu et al., 2015, 2018). Furthermore, Liu et al. (2015) observed a reduction in bast content and thickness of the primary bast fiber layer in stems with plant maturity, which was related to the development and ripening of the seeds. Bast fibers of hemp are bundles of phloem cells derived from the vascular bundles of stems, with primary bast fibers derived from the procambium and secondary bast fibers from the vascular cambium (Gorshkova et al., 2012). One way in which the quality of hemp fibers can be improved is to reduce the proportion of more lignified and shorter secondary bast fibers relative to primary bast fibers (Amaducci et al., 2015).

With the aim to identify key genes related to hemp fiber quality, Van den Broeck and co-workers (Van den Broeck et al., 2008) studied differential expression profiles of over 1,000 unique hemp genes in bast tissue versus the more lignified core tissue during development. They found that hemp genes acting in five interconnected metabolic pathways (pentose phosphate pathway, shikimate pathway, aromatic amino acid biosynthesis, lignin biosynthesis, and one-carbon metabolism) were upregulated in the lignified core tissue, suggesting a direct or indirect link with lignin. Most of these genes were also found to be expressed in the bast fiber tissue but at a much lower level. The relative expression levels of some lignin-related genes increased during development. For instance, a gene with homology to caffeoyl-CoA O-methyltransferase involved in lignin biosynthesis peaked in bast tissue at 91 days after sowing. More recently, Guerriero et al. (2017) performed annotation and transcriptional profiling (RNAseq) of over 3,000 transcript assemblies in bast fiber tissues derived from different hemp stem sections. It was observed that in comparison to other stem sections, the transcriptome of the older internodes showed enrichment for phytohormone-related genes (e.g., genes involved in auxin metabolism, and gibberellic acid, abscisic acid, and jasmonic acid biosynthesis), together with genes involved in noncellulosic polysaccharide deposition and lignification. This is in accordance with a high degree of lignification in more mature fiber tissues at the bottom of the stems and gives many leads to candidate genes for further functional analysis (Table 3). The important role of jasmonic acid in the stimulation of secondary growth was strengthened by the observations of Behr et al. (2018b) who showed that exogenous application of jasmonic acid on young hemp plantlets stimulated the formation of additional secondary phloem fibers and enhanced the lignin content. Putative candidate hemp genes for the biosynthesis of monolignols, their oxidative coupling (laccases and class III peroxidases), lignin deposition (dirigent-like proteins), and stereo-conformation of lignans (dirigent proteins) were studied in more detail (on the gene expression and protein level) underpinning their putative functional relation to lignification of hemp bast fibers (Behr et al., 2018a).
In Arabidopsis, specific miRNAs (small non-protein coding RNA molecules; microRNA; miRNAs) in the leaves function as a signaling system that allows the plant to monitor the progress in development to adulthood and adequately help to time and to induce the flowering stage. This signaling operates via a balance between the amounts of two miRNAs, miR156 and miR172. From the juvenile to adult stage of Arabidopsis, a decrease in miR156 and an increase in miR172 in the leaves are observed. Expression of miR156 can repress adult leaf traits and flowering by binding and inhibiting the genes coding for squamosa promoter-binding-like (SPLs) transcription factors that allow floral transition by activating miR172. In contrast, miR172 promotes flowering and adult leaf traits (Wu et al., 2009; Matsoukas, 2014). In the short-day crop soybean, miR156 and $m i R 172$ were shown to be regulated by photoperiod. Indeed, in soybean, lower miR156 levels (repressor of flowering) and higher miR172 (inducer of flowering) levels were observed under SD than LD photoperiods (Li et al., 2015; SánchezRetuerta et al., 2018). Interestingly, miR156 members also function in the phenylpropanoid biosynthesis pathway, where a miR156-targeted SPL9 has been shown to regulate the metabolic flux during flavonoid biosynthesis (Gou et al., 2011; Gupta et al., 2017). The expression of miRNA families (csa-miR156, csa-miR159a, csa-miR171b, csa-miR172a, csa-miR5021a, csamiR6034) is in silico predicted in hemp (Das et al., 2015; Hasan et al., 2016). However, to date no further information is available on the regulatory patterns of specific miRNAs in hemp. An interesting research question would be if lignin and secondary cell wall deposition that occurs around flowering can be attributed to specific miRNAs. Due to the presence of lignification and high variation in flower characters, hemp seems to be an ideal model crop to study interactions between signaling pathways which is expected to result in the identification of efficient molecular tools to improve the fiber quality in hemp.

\section{THE DIVERSE ROLES OF GIBBERELLIC ACID AND OTHER PHYTOHORMONES}

Another player in the regulation of flowering-time is the phytohormone gibberellic acid (GA). Gibberellins are known to be required for normal growth and development in several species. In Arabidopsis, gibberellins are known to be involved in the "gibberellic acid (GA)-dependent flowering pathway" by regulating AtSOC1 and the floral meristem identity gene LEAFY (AtLFY) (Moon et al., 2003; Mutasa-Göttgens and Hedden, 2009). The GA-dependent growth-regulated pathway is connected with the light regulatory pathway and the circadian clock via PHYTOCHROME INTERACTING FACTORS (PIFs). PIFs are regulated by light through phytochrome, and the interaction with the GA-regulated DELLA proteins can block their activity, and thereby suppress the ability of PIFs to promote gene expression and growth (Mutasa-Göttgens and Hedden, 2009; Leivar and Monte, 2014). Also, the biosynthesis pathway of gibberellins is regulated by several endogenous and environmental factors including light, developmental stage, and hormone balance (Hedden and Phillips, 2000). 
Changes in active GA levels that occur for instance in response to altering light intensities influence plant cell development and the cell wall composition (e.g., Falcioni et al., 2018). The enzyme GIBBERELLIN 20 OXIDASE (GA20 OX) is a key enzyme in the formation of bioactive GAs, whereas GIBBERELLIN 2 OXIDASE (GA2 OX) acts in the opposite way by inactivating bioactive GAs. Both enzymes were shown to modulate plant growth when modified genetically. Overexpression of GA20 OX in various plant species resulted in e.g., increased seed yields, biomass increase, longer xylem fibers, longer and larger leaves whereas knockdown of GA2 OX resulted in increased (tobacco) growth and fiber production (reviewed in de Lima et al., 2017). Transgenic tobacco plants expressing the Arabidopsis genes GA20 $O X$ or GA2 OX show high or low GA levels, respectively, resulting in elongated or stunted pants, respectively. The effects on dry matter accumulation that were found among these transgenic tobacco plants were most likely due to changes in lignin deposition due to upregulation of genes acting in lignin biosynthesis at increased GA levels (Biemelt et al., 2004). Overexpression of GA2 OX in Jatropha and Arabidopsis induced dwarfs with smaller leaves, flowers, and fruits, with a late flowering effect observed only in the latter (Hu et al., 2017). In hemp, exogenous application of GA is used to induce male flowers on female plants, but male plants showed no change in sex determination when treated with GAs (Mohan Ram and Jaiswal, 1972). Exogenous application of GA on leaves increased the growth of hemp and the treated plants showed a greater number of fibers compared to controls. The individual fibers were larger in diameter, more lignified, and up to 10 times as long as the fibers from the untreated plants (Atal, 1961). Application of the phytohormone jasmonic acid to young hemp plantlets resulted in an increased secondary growth as well as the formation of additional secondary phloem fibers, increase in lignin deposition and upregulation of lignin-related genes (Behr et al., 2018b). Also, fibers in the bottom parts of hemp stems were enriched for the expression of genes involved in GA biosynthesis and the biosynthesis of other phytohormones (Guerriero et al., 2017) pointing at the involvement of phytohormones in the regulation of secondary fiber growth.

\section{GENETIC COMPONENTS OF SEX DETERMINATION}

Hemp has a diploid genome $(2 n=20)$ composed of nine pairs of autosomal chromosomes and one pair of sex chromosomes. Like in human, the gender of hemp is known to be influenced by a XY chromosome system. The hemp males are always XY while females carry the XX karyotype (Ainsworth, 2000; Moliterni et al., 2004; Ming et al., 2011; Divashuk et al., 2014; Faux et al., 2014; Razumova et al., 2016). Monoecious hemp, with the female and male flowers located on the same plant, has generally the female XX karyotype (Faux et al., 2014). The key factors that are driving this sexual dimorphism are still unknown (Westergaard, 1958; Ainsworth, 2000; Matsunaga and Kawano, 2001; Ming et al., 2011).
The sex determination seems to be more stable and definite in the male XY karyotype, showing the typical male morphology. However, the ability to develop male flowers on monoecious XX karyotypes shows that the male-determining and/or female-suppressing factors are not necessarily located on the Y chromosome (Faux et al., 2016). To identify sex-linked genomic sequences in hemp, linkage mapping has been performed (Mandolino and Ranalli, 2002; Peil et al., 2003; Faux et al., 2016). Faux and co-workers used populations, segregating for male and female plants, to map several sex-linked QTL loci, putatively located on sex chromosomes. Furthermore, groups of markers co-segregating with sex and with stability of sex determination were found (Faux et al., 2016). Comparison of gene expression (cDNA-AFLP) in early male and female apices resulted in the identification of several differentially expressed fragments, with homology to genes coding for a permease, a ubiquitin (SMT3-like protein), heavy chain of a kinesin 9 protein, and a Rac-GTP binding protein, which may be involved in auxin-regulated gene expression (Moliterni et al., 2004).

Regarding sex determination, an obvious similarity is found between spinach (Spinacia oleracea) and hemp. Like hemp, spinach is dioecious with occasionally monoecious plants in specific lines and crosses, but, in contrast to hemp, no heteromorphic sex chromosomes are observed (Ramanna, 1976). Sex determination in spinach is determined by a locus for sex determination carrying the $\mathrm{Y}$ and $\mathrm{X}$ alleles, whereas monoecy is controlled by a single, incomplete dominant gene on the $\mathrm{M}$ locus that is closely linked to the $\mathrm{X} / \mathrm{Y}$ locus, as was determined in a specific breeding line (Yamamoto et al., 2014). In the presence of the incomplete dominant $M$ allele, female plants (XmXm and XXm) are monoecious whereby the homozygous XmXm plants show a higher degree of male flowers compared to the XXm plants ( $\mathrm{M}$ masks $\mathrm{X}$ ) and, because $\mathrm{Y}$ is dominant over $\mathrm{X}$ and $\mathrm{M}$, YX and YXm plants are male. So, $M$ is a male-promoting, female-suppressing factor but is less effective than the $\mathrm{Y}$ allele. In spinach, monecious lines are used for breeding because of the high degree of homozygosity and high-male monoecious lines are wanted therefore as male parents in breeding programs (Yamamoto et al., 2014). Also, in both spinach and hemp, gibberellins promote masculinization. Recently, West and Golenberg (2018) studied the role of gibberellic acid signaling (GA) in sex determination of spinach and came up with an interesting model for the action of genes underlying sex determination in spinach. They observed differential expression of the GIBBERELLIC ACID INSENSITIVE gene (SpGAI), which is a transcription factor of the DELLA family, among female and male inflorescences, with a high $s p G A I$ expression observed in female inflorescences. Based on gene function analysis studies, a signaling pathway toward sex determination was proposed in reaction to GA application. In short: high levels of GA inhibit SpGAI. GAI inhibits the expression of spinach B-class homeotic genes, which are masculinizing factors that stimulate male organ formation and at the same time suppress the development of female organs in flower primordia. 
So, in conditions of high GA levels (external GA application), the GAI content is reduced, resulting in the release of the inhibition on the B-class homeotic genes, formation of male organs, and inhibition of female organ development. Indeed, in female inflorescences, a two-fold higher expression of SpGAI was observed compared to male plants, which is in agreement with a higher GAI content leading to female organ development.

\section{PLEIOTROPIC EFFECTS AND CARBON PARTITIONING}

Variation in flowering-time is often linked to variation in developmental traits such as plant height, ear height (in maize), seed yield, seed quality traits, leaf number, cell wall composition, and secondary growth [Melzer et al., 2008 (Arabidopsis); Durand et al., 2012 (maize); Vanous et al., 2018 (maize); Cober and Morrison, 2010 (soybean); Shen et al., 2018 (Brassica napus); Copley et al., 2018 (soybean); Petit et al., in preparation (hemp)]. Members of the FT gene family may be involved in these pleiotropic effects (see above), but also other genes operating in signaling networks may connect flowering traits with development and growth. For instance, based on expression network profiling using a lateflowering, woody double mutant (soc1ful) of Arabidopsis (Melzer et al., 2008), three genes with dual function in growth and flowering were indicated as potential candidates for the link between the flowering pathway and growth (XAL1, $A N 3$, and REM1) of which one, $A N 3$, has FT-like properties (Davin et al., 2016).

This correlation of traits complicates selection procedures since negative co-effects on traits have to be considered. An example is soybean, where earliness is often accompanied by a loss in seed yield and quality. To examine these pleiotropic side effects of early flowering, a series of isogenic soybean lines carrying "photoperiod insensitive alleles" (at loci E1, E2, E3, E4, and E7 for early flowering, under LD, see above) was monitored for multiple agronomic traits. The whole series of isogenic lines, including lines with mutations in multiple loci, provided a range of flowering-times, maturities, and yields. For isogenic lines with a single mutant locus, early flowering was often associated with shorter plants, reduced lodging, and early maturity but unfortunately also with reduced seed yields. Among the lines with multiple mutations, some interesting lines with zero yield reduction were found, which might be due to additive or epistatic effects of combined alleles (Cober and Morrison, 2010). In a search for novel loci and genes for photoperiod insensitivity and maturity in soybean, Copley et al. (2018) performed genome-wide association studies (GWAS) and identified several novel loci for maturity traits. However, as most traits were correlated, also most QTLs were co-localized. This correlation of phenotypes can be explained by either a clustering of several genes in a locus or by a "pleiotropic effect" of a single gene on several traits.
Such correlated changes in phenotypic patterns may reflect the shifts in carbon partitioning that take place during development, which affect the overall plant morphology. In earlier varieties, less biomass is accumulated in stem and leaves and therefore less carbon is available for seed production. Interestingly, overexpression of an AGAMOUS-like MADS-box transcription factor, GmAGL1, induced early flowering in soybean, but without negative effects on seed production or on oil and protein content in seeds (Zeng et al., 2018). The only pleiotropic effect of earliness in these transgenic lines was that they had smaller petals and shortened inflorescences. Based on this, it was hypothesized that the transgenic plants may compensate for the energy required for developing fruiting organs by reducing a further allocation to vegetative organs (shortened inflorescences and slightly reduced growth of petals).

In Arabidopsis, it was shown that the shift in carbon partitioning during development is tightly controlled and involves the action of sucrose transporters (SUTs), hexose transporters (STPs) that function in uptake to a cell, and SWEET transporters for export out of the cell, as well as sucrose cleavage enzymes such as cell wall invertases (CINs), vacuolar invertases (VINs), and sucrose synthases (SUSs). In addition to their multiple functions, including acting as energy source (sugars), storage molecules (starches) and structural components (fibers), carbohydrates can also act as signaling molecules (Cho et al., 2018 and references therein). Trehalose6-phosphate (T6P) and Hexokinase 1 (HXK1) are such important signaling metabolites, regulating carbon assimilation and sugar status in plants. At flower induction, sugar consumption for growth reduces and the remaining glucose that is accumulating in the phloem of leaves can eventually promote expression of florigens, while trehalose-6-phosphate functions in the shoot apical meristem to promote the flowering signal pathway downstream of those florigens (Ponnu et al., 2011; Matsoukas, 2014; Cho et al., 2018).

In hemp, the upregulation of genes acting in lignin biosynthesis in older bast fibers (Guerriero et al., 2017) may reflect carbon partitioning toward lignin biosynthesis in phloem tissues around flowering.

\section{A CANDIDATE GENE APPROACH TOWARD GENETIC CONTROL OF HEMP PHENOLOGY AND FIBER QUALITY}

Flowering-time, sex determination, and fiber quality of hemp are quantitative traits that are governed by many genetic loci, each with a certain effect on the phenotype in a specific environment or at a certain developmental stage, or in general. A "candidate gene approach" can contribute to the knowledge about traits. The identification of biosynthesis and signal routes that play a role in the traits enables the identification of candidate genes with the greatest effects on the downstream phenotype, and the prediction of pleiotropic effects on other traits. A selection of genes that are hypnotized to have profound 
effects on phenology and bast fiber quality in fiber hemp are shown in Tables 1-3.

Hemp orthologs for genes acting in flowering-time signaling pathways are putative candidate genes for the regulation of flowering-time in the SD plant hemp. A selection of promising candidates is shown in Table 1 .

The most obvious candidates are orthologs of the "GI-CO-FT" core genes of the "photoperiodic pathway" and genes coding for the phytochrome receptors. In other SD crops, early flowering was often observed in plants carrying nonsense mutations in genes that are repressors of flowering in LD conditions (e.g., orthologs to soybean E1 to E4 genes, (Langewisch et al., 2017) and orthologs of rice Ghd7, Ghd8, PRR37, and phyB (e.g., Xue et al., 2008). Later flowering can for instance be found in plants with nonsense mutations in the florigens or other genes that stimulate flowering (Cai et al., 2018).

When considering a candidate gene, one has to take into account that many genes acting in the flowering-time signaling networks have pleiotropic effects on other traits or may belong to a gene family of which the individual family members have

TABLE 1 | A selection of candidate genes for controlling flowering-time in the short-day crop hemp.

\begin{tabular}{|c|c|c|c|}
\hline Candidate gene & Protein description/ortholog & Function (species) & Reference \\
\hline E2 & GIGANTEA & Photoperiod sensitivity (Soybean) & Watanabe et al., 2011 \\
\hline GmPhyA2 & Phytochrome A & Photoperiod sensitivity (Soybean) & Liu et al. (2008) \\
\hline GmPhyA3 & & & Watanabe et al. (2009) \\
\hline GmFT2a, GmFT5a & FLOWERING LOCUS T & Promoting flowering (Soybean) & Kong et al., 2010 \\
\hline GmFT4 and E1 & FLOWERING LOCUS T & Repressors of GmFT2a and GmFT5a in LD (Soybean) & $\begin{array}{l}\text { Samanfar et al., } 2017 \\
\text { Xia et al., } 2012\end{array}$ \\
\hline$J$ & EARLY FLOWERING 3 & $\begin{array}{l}\text { Relieving the suppression of } F \text { expression } \\
\text { by E1; loss of function alleles show delayed } \\
\text { flowering (Soybean) }\end{array}$ & Lu et al., 2017 \\
\hline HDЗА & $\begin{array}{l}\text { HEADING DATE } 3 A \\
\text { FLOWERING LOCUS T }\end{array}$ & Promotes flowering in SD (Rice) & $\begin{array}{l}\text { Monna et al., } 2002 \\
\text { Kojima et al., } 2002\end{array}$ \\
\hline$R F T 1$ & RICE FLOWERING LOCUS T 1 & Promotes flowering in SD and LD (Rice) & $\begin{array}{l}\text { Komiya et al., 2008, } \\
2009\end{array}$ \\
\hline OsMADS50 & MADS-box transcription factor 50/AtSOC1 & Promotes flowering in LD (Rice) & $\begin{array}{l}\text { Ryu et al., 2009; } \\
\text { Komiya et al., } 2009\end{array}$ \\
\hline EHD1 & Two-component response regulator ORR30 & Promotes flowering in SD (Rice) & Doi et al., 2004 \\
\hline HD1 & Zinc finger protein HD1/CONSTANS & Inhibition of flowering in LD (Rice) & Hayama et al., 2003 \\
\hline OsPhyB & Phytochrome B & & Dehesh et al., 1991 \\
\hline GHD7 & Transcription factor GHD7 & & Xue et al., 2008 \\
\hline GHD8/HD5 & Nuclear transcription factor $Y$ subunit B-11 & & Yano et al., 2001 \\
\hline PRR37 & Two-component response regulator-like PRR37 & & Yano et al., 2001 \\
\hline FLC & $\begin{array}{l}\text { MADS-box protein FLOWERING LOCUS C, } \\
\text { AGAMOUS-LIKE } 25\end{array}$ & $\begin{array}{l}\text { Temperature-dependent flowering. } \\
\text { Repressor of flowering } \\
\text { (Arabidopsis) }\end{array}$ & $\begin{array}{l}\text { Michaels and } \\
\text { Amasino, } 1999\end{array}$ \\
\hline
\end{tabular}

LD, long-day photoperiod; SD, short-day photoperiod.

TABLE 2 | A selection of candidate genes for sex determination, growth, and development in hemp.

\begin{tabular}{|c|c|c|c|}
\hline Candidate gene & Protein description/ortholog & Function (species) & Reference \\
\hline GAl-like & DELLA protein GAI & $\begin{array}{l}\text { May inhibit B-class homeobox genes that } \\
\text { promote male organ development. Upregulated } \\
\text { in female inflorescences of spinach (Spinach) }\end{array}$ & $\begin{array}{l}\text { Peng et al., } 1997 \\
\text { Dill et al., } 2001 \\
\text { West and Golenberg, } 2018\end{array}$ \\
\hline GID1 & Gibberellin receptor GID1 & $\begin{array}{l}\text { Gibberellin (GA) receptor; interacts with } \\
\text { DELLA proteins in the presence of } \\
\text { GA4 (Rice, Arabidopsis) }\end{array}$ & $\begin{array}{l}\text { Nakajima et al., } 2006 \\
\text { Griffiths et al., } 2006 \\
\text { Ueguchi-Tanaka et al., } 2005\end{array}$ \\
\hline GA200X & Gibberellin 20 oxidase & $\begin{array}{l}\text { Key oxidase enzymes in the biosynthesis of } \\
\text { gibberellin (Rice, Arabidopsis) }\end{array}$ & $\begin{array}{l}\text { Phillips et al., } 1995 \\
\text { Rieu et al., 2008a }\end{array}$ \\
\hline GA2OX & Gibberellin 2-beta-dioxygenase & $\begin{array}{l}\text { Catabolism of biologically active gibberellins; } \\
\text { GA homeostasis (Rice, Arabidopsis) }\end{array}$ & $\begin{array}{l}\text { Thomas et al., } 1999 \\
\text { Rieu et al., 2008b }\end{array}$ \\
\hline$S P L$ & $\begin{array}{l}\text { Squamosa promoter-binding-like } \\
\text { transcription factors }\end{array}$ & $\begin{array}{l}\text { A family of plant-specific transcript factors } \\
\text { that play crucial roles in the regulation of plant } \\
\text { growth and development }\end{array}$ & $\begin{array}{l}\text { Klein et al., } 1996 \\
\text { Preston and Hileman, } 2013 \\
\text { Liu et al., } 2016\end{array}$ \\
\hline
\end{tabular}

Genes involved in gibberellic acid signaling (GA) and DELLA transcription factors are interesting candidate genes for all three hemp traits: flowering-time, sex determination, and fiber quality, depending on the specific developmental stage and/or tissue where they are expressed. 
TABLE 3 | A selection of candidate genes for bast fiber quality in hemp.

\begin{tabular}{|c|c|c|c|}
\hline Candidate gene & Protein description/ortholog & Function (species) & Reference \\
\hline WAT1 & WALLS ARE THIN & $\begin{array}{l}\text { Auxin efflux transporter required for secondary wall } \\
\text { formation in fibers (Arabidopsis); upregulated in bast fibers } \\
\text { of older, thicker, and more lignified stem sections (Hemp) }\end{array}$ & $\begin{array}{l}\text { Ranocha et al., 2010; } \\
\text { Guerriero et al., } 2017\end{array}$ \\
\hline OMT1 & Flavone 3'-O-methyltransferase 1 & $\begin{array}{l}\text { Catalyzes the methylation of monolignols, the lignin } \\
\text { precursors; upregulated in bast fibres of older, thicker, and } \\
\text { more lignified hemp stem sections (Arabidopsis; Hemp) }\end{array}$ & $\begin{array}{l}\text { Moinuddin et al., 2010; Van den Broeck } \\
\text { et al., 2008; } \\
\text { Guerriero et al., } 2017\end{array}$ \\
\hline CCOAOMT & Caffeoyl-CoA O-methyltransferase 1 & $\begin{array}{l}\text { Synthesis of feruloylated polysaccharides; upregulated in } \\
\text { bast fibres of older, thicker, and more lignified hemp stem } \\
\text { sections (Arabidopsis; Hemp) }\end{array}$ & $\begin{array}{l}\text { Do et al., 2007; } \\
\text { Guerriero et al., } 2017\end{array}$ \\
\hline $\begin{array}{l}\text { NAC } \\
\text { MYB4 }\end{array}$ & $\begin{array}{l}\text { MYB and NAC domain containing } \\
\text { protein }\end{array}$ & $\begin{array}{l}\text { Involved in lignin biosynthesis; several are upregulated in } \\
\text { bast fibres of older, thicker, and more lignified hemp stem } \\
\text { sections (Hemp) }\end{array}$ & $\begin{array}{l}\text { Zhao and Dixon, 2011; Guerriero et al., } \\
\text { 2017; Behr et al., 2018a }\end{array}$ \\
\hline $\begin{array}{l}D L P 4 \\
D L P 5\end{array}$ & Dirigent-like proteins & Putatively involved in lignin deposition (Hemp) & Behr et al., 2018a \\
\hline $\operatorname{IR} X 12$ & Laccase 4 & $\begin{array}{l}\text { Oxidative coupling of monolignols (H, G, S-units) } \\
\text { (Arabidopsis); upregulated in bast fibres of older, thicker, } \\
\text { and more lignified hemp stem sections (Hemp) }\end{array}$ & $\begin{array}{l}\text { Brown et al., 2005; Zhao et al., 2013; } \\
\text { Guerriero et al., 2017; Behr et al., 2018a }\end{array}$ \\
\hline $\begin{array}{l}\angle O X 2 \\
4 C L L 7\end{array}$ & $\begin{array}{l}\text { Lipoxygenase } 2 \\
4 \text { Coumarate CoA ligase-like } 7\end{array}$ & Jasmonic acid biosynthesis (Arabidopsis; Hemp) & $\begin{array}{l}\text { Bell and Mullet, 1993; Schneider et al., } \\
\text { 2005; Guerriero et al., 2017; Behr et al., } \\
\text { 2018b }\end{array}$ \\
\hline
\end{tabular}

Genes involved in gibberellic acid signaling (GA) and DELLA transcription factors (see Table 2) are interesting candidate genes for all three hemp traits: flowering-time, sex determination, and fibre quality, depending on the specific developmental stage and/or tissues where they are expressed.

different functions. For instance, the "circadian clock" genes such as GI, and other "circadian" genes involved in regulation of flowering-time are involved in many biological processes, and can result in pleiotropic effects on for instance floral transition, leaf movement, stomata opening, seed germination, and hypocotyl elongation (e.g., Ding et al., 2007; Kolmos et al., 2009; Wenden et al., 2011; Mishra and Panigrahi, 2015; Shim and Imaizumi, 2015). Also, squamosa promoter-binding-like proteins (SPLs) belong to a family of functionally specialized transcription factors with multiple roles in plant phase transition, flower and fruit development, plant architecture, gibberellins signaling, sporogenesis, and response to copper and fungal toxins (Preston and Hileman, 2013).

Regarding sex determination, genes involved in gibberellic acid signaling (GA) and DELLA transcription factors are interesting candidate genes that may also have a side effect on fiber quality (Tables 2, 3).

In a situation where different quantitative characteristics have to be combined, the ability to select in an early stage for plants with specific flowering characteristics would already be an important step for breeding. Genetic variation at candidate gene loci can be utilized to select specific haplotypes via "haplotype tagging SNPs" (htSNPs). These htSNPs improve the efficiency of association studies performed for the selection of alleles in the population that are associated with phenotypic variation in the trait (Ehrenreich et al., 2009). In short-day crops such as soybean and rice, molecular markers for maturity and flowering-time based on genetic variation in candidate genes for flowering-time are already used (e.g., Langewisch et al., 2017 (soybean); Shabir et al., 2017 (rice)). In hemp, molecular markers have mostly been developed for forensic studies to differentiate drug-type cannabis from hemp or for the early detection of male plants (Mandolino et al., 2002; reviewed in Onofri and Mandolino, 2017).

It should also be stressed that finding "candidate genes" across species has limitations because the function of candidate genes across species may be similar but often not identical (e.g., Salentijn et al., 2007; Wong et al., 2014). So, a prerequisite for a successful application of the "candidate gene approach" is functional knowledge of candidate genes in hemp. At present, the knowledge of gene function and gene expression in Cannabis sativa is still limited, and mainly focused on genes acting in cannabinoid biosynthesis. Several molecular technologies such as "genome editing" and "targeted mutagenesis" contribute to gene functional analysis and to the generation of plants with specific mutations. Genome editing by the CRISPR/Cas9 system appears to be a very precise and efficient tool for functional analysis of specific genes and the development of useful mutants in several crops (e.g., Hille et al., 2018; Schindele et al., 2018). The system yet requires genetic transformation and regeneration of transgenic CRISPR/Cas9 plants from undifferentiated cells (callus tissue) or protoplasts. Regarding hemp, protocols for shoot regeneration from callus are known, but these work efficiently only for specific hemp accessions (Andre et al., 2016; Chaohua et al., 2016) and, to our knowledge, cases of efficient production of transgenic hemp plants produced via Agrobacterium-mediated genetic transformation have not been published yet. As such, hemp is still considered a recalcitrant plant for genetic modification and thus for CRISPR/Cas9.

If mutants can be obtained in a less recalcitrant hemp cultivar, the specific mutations in such transgenic lines can be delivered to breeding lines via cross breeding. However, this will introduce also unwanted traits and the Cas9-gRNA 
cassette in the receiving parent, and many subsequent breeding steps are required to restore original traits. Recently, Kelliher et al. (2019) and Wang et al. (2019) published a new approach (Haploid-Inducer Mediated Genome Editing) to overcome such problems in maize cultivars. This approach combines the technology of haploid induction with CRISPR/Cas9 genome editing and requires specific haploid inducer lines (e.g., carrying homozygous mutations in CENH3 for dicots) that are stably transformed with constructs expressing the CRISPR Cas9-gRNA editing tools. The gametes of such lines can transfer the editing tools to recalcitrant cultivars ( $v i a$ cross breeding instead of genetic transformation). Due to the haploid inducer, the genome carrying both, the CRISPR sequences and the haploid inducer trait is eliminated short after fertilization and haploid embryos of are formed that, upon chromosome doubling, can grow into plants that yield $100 \%$ inbred seed. It appeared that the short time of interaction of the two genomes after fertilization was enough to induce specific mutations in the recipient genome. Above all, the CRISPR genes are not present in genome of the resulting crop which can be advantageous in connection with GMO regulations. Application of this system in hemp is not to be expected in the short term since transformable hemp accessions, together with a haploid induction system, are not immediately available.

Targeted mutagenesis or TILLING (McCallum et al., 2000) is another way to select for plants with mutations in specific genes. For this strategy, seeds or pollen are treated with specific chemicals that make point-mutations at random throughout the genome. Large populations of mutated plants are then screened for the presence of mutations in specific genes using high throughput sequencing, or other screening technologies. This strategy was used in hemp to find plants with specific induced knock-out and missense mutations in CsFAD2 and CsFAD3 genes leading to altered seed-oil composition in the seed hemp variety Finola (Bielecka et al., 2014). Such a strategy requires facilities to grow large mutant populations and for seed storage and breeding steps to obtain homozygous mutations or combine different mutations.

A very useful tool for hemp genomics is the draft genome sequence of hemp (covering $534 \mathrm{Mb}$ of the haploid hemp genome that is $818-843 \mathrm{Mb}$ in size) published by Van Bakel et al. (2011), including more than 30,000 transcript assemblies (NCBI TSA: JP449145.1 to JP482359.1; PK00001.1 to PK29878.1), and the "in silico" gene expression profiles of these genes (Massimino, 2017). Two initiatives to improve the hemp genome were undertaken that independently resulted in the assembly of the hemp genome in 10 pseudomolecules (scaffolds, separated by gaps) representing the 10 different chromosomes of hemp $(2 n=2 x=20)$ (Grassa et al., 2018; Laverty et al., 2018). It was experienced that the assembly of the hemp genome was complicated by the presence of large quantities of repetitive DNA $(\sim 73 \%$ of the hemp genome), the heterozygous character of hemp (Van Bakel et al., 2011; Sawler et al., 2015), and an expected high degree of karyotype polymorphisms among hemp varieties (Razumova et al., 2016). This situation was approached by using long-read sequencing technologies (PacBio SMRT, Nanopore sequencing) next to the standard Illumina sequencing technology to span large stretches of repetitive DNA. For the assembly of the genome, a combination of physical and genetic mapping was applied (Laverty et al., 2018). It was found that most recombination events occurred in the gene-rich regions near the chromosome ends. Furthermore, three pseudomolecules appeared to have recombination only on a single arm of the chromosome (telocentric) and one of these may represent the sex chromosome whereas the other two may represent the chromosomes that harbor 5SrDNA and 45SrDNA (Laverty et al., 2018). The map is still not completed (see NCBI assembly no. GCA_003417725.2 \& GCA_000230575.4; GCA_900626175.1) and not all known transcripts and malespecific markers could be mapped. Dedicated genetic mapping and sequencing strategies may further unravel the complex genetic structure of the hemp genome, and may detect hemp lines that accommodate specific genetic variation.

\section{CONCLUDING REMARKS}

Here we review aspects of the traits "flowering-time," "sex determination," and "fiber quality" that are relevant to hemp. This information can be utilized to predict putative candidate genes, which can serve as targets for the development of molecular markers for these traits. For the development of such breeding tools, it is important to know the allelic variation underlying candidate genes that is responsible for the phenotypic variation. A big advantage for hemp is the presence of a high level of natural genotypic and phenotypic variation which makes it possible to perform efficient GWAS studies to validate the putative biological function of candidate genes, and to discover novel genomic regions involved. Furthermore, we like to point to the importance of high throughput phenotyping protocols which are needed to map QTL loci, including small effect loci.

\section{AUTHOR CONTRIBUTIONS}

ES and LT were involved in the conceptualization of the review. ES wrote the manuscript. LT and JP revised the manuscript. All authors approved the manuscript.

\section{FUNDING}

This research was conducted as part of the MultiHemp project (Multipurpose hemp for industrial bioproducts and biomass) funded by the European Union's Seventh Framework Programme for research, technological developments and demonstration under grant agreement number 311849, and co-funded by the Dutch Ministry of Agriculture (LVN) as part of the research theme "Total use of Resources for Food and Materials." 


\section{REFERENCES}

Ainsworth, C. (2000). Boys and girls come out to play: the molecular biology of dioecious plants. Ann. Bot. 86, 211-221. doi: 10.1006/anbo.2000.1201

Amaducci, S., Colauzzi, M., Bellocchi, G., Cosentino, S. L., Pahkala, K., Stomph, T. J., et al. (2012). Evaluation of a phenological model for strategic decisions for hemp (Cannabis Sativa L.) biomass production across European sites. Ind. Crop. Prod. 37, 100-110. doi: 10.1016/j.indcrop.2011.11.012

Amaducci, S., Colauzzi, M., Bellocchi, G., and Venturi, G. (2008b). Modelling post-emergent hemp phenology (Cannabis sativa L.): theory and evaluation. Eur. J. Agron. 28, 90-102. doi: 10.1016/j.eja.2007.05.006

Amaducci, S., Colauzzi, M., Zatta, A., and Venturi, G. (2008a). Flowering dynamics in monoecious and dioecious hemp genotypes. J. Ind. Hemp 13, 5-19. doi: 10.1080/15377880801898691

Amaducci, S., Scordia, D., Liu, F. H., Zhang, Q., Guo, H., Testa, G., et al. (2015). Key cultivation techniques for hemp in Europe and China. Ind. Crop. Prod. 68, 2-16. doi: 10.1016/j.indcrop.2014.06.041

Andre, C. M., Hausman, J. F., and Guerriero, G. (2016). Cannabis sativa: the plant of the thousand and one molecules. Front. Plant Sci. 7:19. doi: 10.3389/ fpls.2016.00019

Atal, C. K. (1961). Effect of gibberellin on the fibers of hemp. Econ. Bot. 15, 133-139. doi: 10.1007/BF02904086

Barth, M., and Carus, M. (2015). Carbon footprint and sustainability of different natural fibres for biocomposites and insulation material: study providing data for the automotive and insulation industry. Report nova-Institut $\mathrm{GmbH}$. Version 2015-04. http://hempinc.com/wp-content/uploads/2016/01/15-04Carbon-Footprint-of-Natural-Fibres-nova1.pdf

Behr, M., Lutts, S., Hausman, J.-F., and Guerriero, G. (2018b). Jasmonic acid to boost secondary growth in hemp hypocotyl. Planta 248, 1029-1036. doi: 10.1007/s00425-018-2951-5

Behr, M., Sergeant, K., Leclercq, C. C., Planchon, S., Guignard, C., Lenouvel, A., et al. (2018a). Insights into the molecular regulation of monolignol-derived product biosynthesis in the growing hemp hypocotyl. BMC Plant Biol. 18:1. doi: 10.1186/s12870-017-1213-1

Bell, E., and Mullet, J. E. (1993). Characterization of an Arabidopsis lipoxygenase gene responsive to methyl jasmonate and wounding. Plant Physiol. 103, 1133-1137. doi: 10.1104/pp.103.4.1133

Berenji, J., Sikora, V., Fournier, G., and Beherec, O. (2013). "Genetics and selection of hemp" in Hemp industrial production and uses. eds. P. Bouloc, S. Allegret, and L. Arnaud (Wollingford, UK: CABI), 48-71.

Bielecka, M., Kaminski, F., Adams, I., Poulson, H., Sloan, R., Li, Y., et al. (2014). Targeted mutation of Delta 12 and Delta 15 desaturase genes in hemp produce major alterations in seed fatty acid composition including a high oleic hemp oil. Plant Biotechnol. J. 12, 613-623. doi: 10.1111/pbi.12167

Biemelt, S., Tschiersch, H., and Sonnewald, U. (2004). Impact of altered gibberellin metabolism on biomass accumulation, lignin biosynthesis, and photosynthesis in transgenic tobacco plants. Plant Physiol. 135, 254-265. doi: 10.1104/ pp.103.036988

Borthwick, H. A., and Scully, N. J. (1954). Photoperiodic responses of hemp. Bot. Gaz. 116, 14-29. doi: 10.1086/335843

Bouché, F., Detry, N., and Perilleux, C. (2015). Heat can erase epigenetic marks of vernalization in Arabidopsis. Plant Signal. Behav. 10:e990799. doi: $10.4161 / 15592324.2014 .990799$

Bouché, F., Lobet, G., Tocquin, P., and Perilleux, C. (2016). FLOR-ID: an interactive database of flowering-time gene networks in Arabidopsis thaliana. Nucleic Acids Res. 44, D1167-D1171. doi: 10.1093/nar/gkv1054

Brown, D. M., Zeef, L. A. H., Ellis, J., Goodacre, R., and Turner, S. R. (2005). Identification of novel genes in Arabidopsis involved in secondary cell wall formation using expression profiling and reverse genetics. Plant Cell 17, 2281-2295. doi: 10.1105/tpc.105.031542

Cai, Y. P., Chen, L., Liu, X. J., Guo, C., Sun, S., Wu, C. X., et al. (2018). CRISPR/Cas9-mediated targeted mutagenesis of GmFT2a delays flowering time in soya bean. Plant Biotechnol. J. 16, 176-185. doi: 10.1111/pbi.12758

Callaway, J. C. (2004). Hempseed as a nutritional resource: an overview. Euphytica 140, 65-72. doi: 10.1007/s10681-004-4811-6

Chaohua, C., Gonggu, Z., Lining, Z., Chunsheng, G., Qing, T., Jianhua, C., et al. (2016). A rapid shoot regeneration protocol from the cotyledons of hemp (Cannabis sativa L.). Ind. Crop. Prod. 83, 5-65. doi: 10.1016/j.indcrop.2015.12.035
Chen, Q. G., Payyavula, R. S., Chen, L., Zhang, J., Zhang, C. K., and Turgeon, R. (2018). FLOWERING LOCUS T mRNA is synthesized in specialized companion cells in Arabidopsis and Maryland Mammoth tobacco leaf veins. Proc. Natl. Acad. Sci. USA 115, 2830-2835. doi: 10.1073/pnas.1719455115

Cheng, J. Z., Zhou, Y. P., Lv, T. X., Xie, C. P., and Tian, C. E. (2017). Research progress on the autonomous flowering time pathway in Arabidopsis. Physiol. Mol. Biol. Plants 23, 477-485. doi: 10.1007/s12298-017-0458-3

Cho, L. H., Pasriga, R., Yoon, J., Jeon, J. S., and An, G. (2018). Roles of sugars in controlling flowering time. J. Plant Biol. 61, 121-130. doi: 10.1007/ s12374-018-0081-Z

Christie, J. M., Blackwood, L., Petersen, J., and Sullivan, S. (2015). Plant flavoprotein photoreceptors. Plant Cell Physiol. 56, 401-413. doi: 10.1093/ pcp/pcu196

Cober, E. R., and Morrison, M. J. (2010). Regulation of seed yield and agronomic characters by photoperiod sensitivity and growth habit genes in soybean. Theor. Appl. Genet. 120, 1005-1012. doi: 10.1007/s00122-009-1228-6

Copley, T. R., Duceppe, M. O., and O’Donoughue, L. S. (2018). Identification of novel loci associated with maturity and yield traits in early maturity soybean plant introduction lines. BMC Genomics 19, 167. doi: 10.1186/ s12864-018-4558-4

Das, A., Chaudhury, S., Kalita, M. C., and Mondal, T. K. (2015). In silico identification, characterization and expression analysis of miRNAs in Cannabis sativa L. Plant Gene 2, 17-24. doi: 10.1016/j.plgene.2015.03.003

Davin, N., Edger, P. P., Hefer, C. A., Mizrachi, E., Schuetz, M., Smets, E., et al. (2016). Functional network analysis of genes differentially expressed during xylogenesis in soclful woody Arabidopsis plants. Plant J. 86, 376-390. doi: $10.1111 /$ tpj.13157

Dehesh, K., Tepperman, J., Christensen, A. H., and Quail, P. H. (1991). PhyB is evolutionarily conserved and constitutively expressed in rice seedling shoots. Mol. Gen. Genet. 225, 305-313. doi: 10.1007/BF00269863

Dill, A., Jung, H. S., and Sun, T. P. (2001). The DELLA motif is essential for gibberellin-induced degradation of RGA. Proc. Natl. Acad. Sci. USA 98, 14162-14167. doi: 10.1073/pnas.251534098

Ding, Z., Millar, A. J., Davis, A. M., and Davis, S. J. (2007). TIME FOR COFFEE encodes a nuclear regulator in the Arabidopsis thaliana circadian clock. Plant Cell 19, 1522-1536. doi: 10.1105/tpc.106.047241

Divashuk, M. G., Alexandrov, O. S., Razumova, O. V., Kirov, I. V., and Karlov, G. I. (2014). Molecular cytogenetic characterization of the dioecious Cannabis sativa with an XY chromosome sex determination system. PLoS One 9:e85118. doi: 10.1371/journal.pone.0085118

Do, C. T., Pollet, B., Thevenin, J., Sibout, R., Denoue, D., Barriere, Y., et al. (2007). Both caffeoyl Coenzyme A 3-O-methyltransferase 1 and caffeic acid O-methyltransferase 1 are involved in redundant functions for lignin, flavonoids and sinapoyl malate biosynthesis in Arabidopsis. Planta 226, 1117-1129. doi: 10.1007/s00425-007-0558-3

Doi, K., Izawa, T., Fuse, T., Yamanouchi, U., Kubo, T., Shimatani, Z., et al. (2004). Ehd1, a B-type response regulator in rice, confers short-day promotion of flowering and controls FT-like gene expression independently of Hd1. Genes Dev. 18, 926-936. doi: 10.1101/gad.1189604

Durand, E., Bouchet, S., Bertin, P., Ressayre, A., Jamin, P., Charcosset, A., et al. (2012). Flowering time in maize: linkage and epistasis at a major effect locus. Genetics 190, 1547-1562. doi: 10.1534/genetics.111.136903

Ehrenreich, I. M., Hanzawa, Y., Chou, L., Roe, J. L., Kover, P. X., and Purugganan, M. D. (2009). Candidate gene association mapping of Arabidopsis flowering time. Genetics 183, 325-335. doi: 10.1534/genetics.109.105189

Falcioni, R., Moriwaki, T., de Oliveira, D. M., Andreotti, G. C., de Souza, L. A., Dos Santos, W. D., et al. (2018). Increased gibberellins and light levels promotes cell wall thickness and enhance lignin deposition in xylem fibers. Front. Plant Sci. 9:1391. doi: 10.3389/fpls.2018.01391

Faux, A. M., Berhin, A., Dauguet, N., and Bertin, P. (2014). Sex chromosomes and quantitative sex expression in monoecious hemp (Cannabis sativa L.). Euphytica 196, 183-197. doi: 10.1007/s10681-013-1023-y

Faux, A. M., Draye, X., Flamand, M. C., Occre, A., and Bertin, P. (2016). Identification of QTLs for sex expression in dioecious and monoecious hemp (Cannabis sativa L.). Euphytica 209, 357-376. doi: 10.1007/ s10681-016-1641-2

Faux, A. M., Draye, X., Lambert, R., d'Andrimont, R., Raulier, P., and Bertin, P. (2013). The relationship of stem and seed yields to flowering phenology 
and sex expression in monoecious hemp (Cannabis sativa L.). Eur. J. Agron. 47, 11-22. doi: 10.1016/j.eja.2013.01.006

Galvão, V. C., and Fankhauser, C. (2015). Sensing the light environment in plants: photoreceptors and early signaling steps. Curr. Opin. Neurobiol. 34, 46-53. doi: 10.1016/j.conb.2015.01.013

Gorshkova, T., Brutch, N., Chabbert, B., Deyholos, M., Hayashi, T., Lev-Yadun, S., et al. (2012). Plant fiber formation: state of the art, recent and expected progress, and open questions. Crit. Rev. Plant Sci. 31, 201-228. doi: 10.1080/07352689.2011.616096

Gou, J. Y., Felippes, F. F., Liu, C. J., Weigel, D., and Wang, J. W. (2011). Negative regulation of anthocyanin biosynthesis in Arabidopsis by a miR156targeted SPL transcription factor. Plant Cell 23, 1512-1522. doi: 10.1105/ tpc. 111.084525

Grassa, C. J., Wenger, J. P., Dabney, C., Poplawski, S. G., Motley, S. T., Michael, T. P., et al. (2018). A complete Cannabis chromosome assembly and adaptive admixture for elevated cannabidiol (CBD) content [Preprint]. doi: $10.1101 / 458083$

Griffiths, J., Murase, K., Rieu, I., Zentella, R., Zhang, Z. L., Powers, S. J., et al. (2006). Genetic characterization and functional analysis of the GID1 gibberellin receptors in Arabidopsis. Plant Cell 18, 3399-3414. doi: 10.1105/tpc.106.047415

Guerriero, G., Behr, M., Legay, S., Mangeot-Peter, L., Zorzan, S., Ghoniem, M., et al. (2017). Transcriptomic profiling of hemp bast fibres at different developmental stages. Sci. Rep. 7:4961. doi: 10.1038/s41598-017-05200-8

Gupta, O. P., Karkute, S. G., Banerjee, S., Meena, N. L., and Dahuja, A. (2017). Contemporary understanding of miRNA-based regulation of secondary metabolites biosynthesis in plants. Front. Plant Sci. 8:374. doi: 10.3389/ fpls.2017.00374

Hall, J., Bhattarai, S. P., and Midmore, D. J. (2012). Review of flowering control in industrial hemp. J. Nat. Fibers 9, 23-36. doi: 10.1080/15440478.2012.651848

Hall, J., Bhattarai, S. P., and Midmore, D. J. (2014). The effects of photoperiod on phenological development and yields of industrial hemp. J. Nat. Fibers 11, 87-106. doi: 10.1080/15440478.2013.846840

Hasan, M. A., Hussain, M. H., Chowdhury, A. S., Dhar, S. B., Abedin, M., and Fima, I. N. (2016). Computational identification of potential microRNAs and their targets from expressed sequence tags of marijuana (Cannabis sativa). Meta Gene 10, 45-55. doi: 10.1016/j.mgene.2016.10.002

Hayama, R., Yokoi, S., Tamaki, S., Yano, M., and Shimamoto, K. (2003). Adaptation of photoperiodic control pathways produces short-day flowering in rice. Nature 422, 719-722. doi: 10.1038/nature01549

Hedden, P., and Phillips, A. L. (2000). Gibberellin metabolism: new insights revealed by the genes. Trends Plant Sci. 5, 523-530. doi: 10.1016/ S1360-1385(00)01790-8

Hill, C. B., and Li, C. (2016). Genetic architecture of flowering phenology in cereals and opportunities for crop improvement. Front. Plant Sci. 7:1906. doi: $10.3389 /$ fpls.2016.01906

Hille, F., Richter, H., Wong, S. P., Bratovic, M., Ressel, S., and Charpentier, E. (2018). The biology of CRISPR-cas: backward and forward. Cell 172, 1239-1259. doi: 10.1016/j.cell.2017.11.032

Höppner, F., and Menge-Hartmann, U. (2007). Yield and quality of fibre and oil of fourteen hemp cultivars in Northern Germany at two harvest dates. Landbauforsch. Volk. 57, 219-232.

Hu, Y. X., Tao, Y. B., and Xu, Z. F. (2017). Overexpression of Jatropha gibberellin 2-oxidase 6 (JcGA2ox6) induces dwarfism and smaller leaves, flowers and fruits in Arabidopsis and Jatropha. Front. Plant Sci. 8:2103. doi: 10.3389/ fpls.2017.02103

Hyun, Y., Richter, R., Vincent, C., Martinez-Gallegos, R., Porri, A., and Coupland, G. (2016). Multi-layered regulation of SPL15 and cooperation with SOC1 integrate endogenous flowering pathways at the Arabidopsis Shoot Meristem. Dev. Cell 37, 254-266. doi: 10.1016/j.devcel.2016.04.001

Immink, R. G. H., Pose, D., Ferrario, S., Ott, F., Kaufmann, K., Valentim, F. L., et al. (2012). Characterization of SOC1's central role in flowering by the identification of its upstream and downstream regulators. Plant Physiol. 160, 433-449. doi: 10.1104/pp.112.202614

Jenkins, G. I. (2014). The UV-B photoreceptor UVR8: from structure to physiology. Plant Cell 26, 21-37. doi: 10.1105/tpc.113.119446

Jung, C., Pillen, K., Staiger, D., Coupland, G., and von Korff, M. (2017). Editorial: recent advances in flowering time control. Front. Plant Sci. 7:2011. doi: $10.3389 /$ fpls.2016.02011
Karus, M., and Vogt, D. (2004). European hemp industry: cultivation, processing and product lines. Euphytica 140, 7-12. doi: 10.1007/s10681-004-4810-7

Keller, A., Leupin, M., Mediavilla, V., and Wintermantel, E. (2001). Influence of the growth stage of industrial hemp on chemical and physical properties of the fibres. Ind. Crop. Prod. 13, 35-48. doi: 10.1016/S0926-6690(00)00051-0

Kelliher, T., Starr, D., Su, X., Tang, G., Chen, Z., Carter, J., et al. (2019). Onestep genome editing of elite crop germplasm during haploid induction. Nature Biotechnol. 37, 287-292. doi: 10.1038/s41587-019-0038-x

Klein, J., Saedler, H., and Huijser, P. (1996). A new family of DNA binding proteins includes putative transcriptional regulators of the Antirrhinum majus floral meristem identity gene SQUAMOSA. Mol. Gen. Genet. 250, 7-16 doi: $10.1007 / \mathrm{s} 004380050046$

Klocko, A. L., Ma, C., Robertson, S., Esfandiari, E., Nilsson, O., and Strauss, S. H. (2016). FT overexpression induces precocious flowering and normal reproductive development in Eucalyptus. Plant Biotechnol. J. 14, 808-819. doi: $10.1111 /$ pbi. 12431

Kojima, S., Takahashi, Y., Kobayashi, Y., Monna, L., Sasaki, T., Araki, T., et al. (2002). Hd3a, a rice ortholog of the Arabidopsis FT gene, promotes transition to flowering downstream of $\mathrm{Hd} 1$ under short-day conditions. Plant Cell Physiol. 43, 1096-1105. doi: 10.1093/pcp/pcf156

Kolmos, E., Nowak, M., Werner, M., Fischer, K., Schwarz, G., Mathews, S., et al. (2009). Integrating ELF4 into the circadian system through combined structural and functional studies. HFSP Journal 3, 350-366. doi: $10.2976 / 1.3218766$

Komiya, R., Ikegami, A., Tamaki, S., Yokoi, S., and Shimamoto, K. (2008), $H d 3 a$ and RFT1 are essential for flowering in rice. Development 135, 767-774. doi: $10.1242 /$ dev.008631

Komiya, R., Yokoi, S., and Shimamoto, K. (2009). A gene network for long-day flowering activates RFT1 encoding a mobile flowering signal in rice. Development 136, 3443-3450. doi: 10.1242/dev.040170

Kong, F., Liu, B., Xia, Z., Sato, S., Kim, B. M., Watanabe, S., et al. (2010). Two coordinately regulated homologs of FLOWERING LOCUS T are involved in the control of photoperiodic flowering in soybean. Plant Physiol. 154, 1220-1231. doi: 10.1104/pp.110.160796

Kong, S. G., and Okajima, K. (2016). Diverse photoreceptors and light responses in plants. J. Plant Res. 129, 111-114. doi: 10.1007/s10265-016-0792-5

Langewisch, T., Lenis, J., Jiang, G. L., Wang, D., Pantalone, V., and Bilyeu, K. (2017). The development and use of a molecular model for soybean maturity groups. BMC Plant Biol. 17:91. doi: 10.1186/s12870-017-1040-4

Laverty, K. U., Stout, J. M., Sullivan, M. J., Shah, H., Gill, N., Holbrook, L., et al. (2018). A physical and genetic map of Cannabis sativa identifies extensive rearrangement at the THC/CBD acid synthase locus. Genome Res. 29, 146-156. doi: 10.1101/gr.242594.118

Lee, J., and Lee, I. (2010). Regulation and function of SOC1, a flowering pathway integrator. J. Exp. Bot. 61, 2247-2254. doi: 10.1093/jxb/erq098

Leivar, P., and Monte, E. (2014). PIFs: systems integrators in plant development. Plant Cell 26, 56-78. doi: 10.1105/tpc.113.120857

Li, D., Liu, C., Shen, L., Wu, Y., Chen, H., Robertson, M., et al. (2008). A repressor complex governs the integration of flowering signals in Arabidopsis. Dev. Cell 15, 110-120. doi: 10.1016/j.devcel.2008.05.002

Li, X. P., Wang, S. Q., Du, G. B., Wu, Z. K., and Meng, Y. J. (2013). Variation in physical and mechanical properties of hemp stalk fibers along height of stem. Ind. Crop. Prod. 42, 344-348. doi: 10.1016/j. indcrop.2012.05.043

Li, W. B., Wang, P. P., Li, Y. G., Zhang, K. X., Ding, F. Q., Nie, T. K., et al. (2015). Identification of micrornas in response to different day lengths in Soybean using high-throughput sequencing and qRT-PCR. PLoS One 10:e0132621. doi: 10.1371/journal.pone.0132621

Lifschitz, E., Ayre, B. G., and Eshed, Y. (2014). Florigen and anti-florigen - a systemic mechanism for coordinating growth and termination in flowering plants. Front. Plant Sci. 5:465. doi: 10.3389/fpls.2014.00465

Lima, M. d. F., Eloy, N. B., Siqueira, J. A. B. d., Inzé, D., Hemerly, A. S., and Ferreira, P. C. G. (2017). Molecular mechanisms of biomass increase in plants. Biotechnol. Res. Innovation 1, 14-25. doi: 10.1016/j.biori.2017.08.001

Lisson, S. N., Mendham, N. J., and Carberry, P. S. (2000a). Development of a hemp (Cannabis sativa L.) simulation model 2. The flowering response of two hemp cultivars to photoperiod. Aust. J. Exp. Agric. 40, 413-417. doi: 10.1071/EA99059 
Lisson, S. N., Mendham, N. J., and Carberry, P. S. (2000b). Development of a hemp (Cannabis sativa L.) simulation model 4. Model description and validation. Aust. J. Exp. Agric. 40, 425-432. doi: 10.1071/EA99061

Liu, M., Fernando, D., Daniel, G., Madsen, B., Meyer, A. S., Ale, M. T., et al. (2015). Effect of harvest time and field retting duration on the chemical composition, morphology and mechanical properties of hemp fibers. Ind. Crop. Prod. 69, 29-39. doi: 10.1016/j.indcrop.2015.02.010

Liu, B., Kanazawa, A., Matsumura, H., Takahashi, R., Harada, K., and Abe, J. (2008). Genetic redundancy in soybean photoresponses associated with duplication of the phytochrome A gene. Genetics 180, 995-1007. doi: 10.1534/ genetics.108.092742

Liu, L., Li, B., Xiang, Y. P., Zhang, R. Y., Yu, J. Y., and Fang, B. (2018). Effect of growth period and sampling section on the chemical composition and microstructure of raw hemp fibers. Bioresources 13, 1961-1976. doi: 10.15376/ biores.13.1.1961-1976

Liu, Q., Nicholas, P., Harberd, N. P., and Fu, X. (2016). SQUAMOSA promoter binding protein-like transcription factors: targets for improving cereal grain yield. Mol. Plant 9, 765-767. doi: 10.1016/j.molp.2016.04.008

Lu, S., Zhao, X., Hu, Y., Liu, S., Nan, H., Li, X., et al. (2017). Natural variation at the soybean $J$ locus improves adaptation to the tropics and enhances yield. Nat. Genet. 49, 773-779. doi: 10.1038/ng.3819

Mandolino, G., Carboni, A., Bagatta, M., Moliterni, V. M. C., and Ranalli, P. (2002). Occurrence and frequency of putatively Y chromosome linked DNA markers in Cannabis sativa L. Euphytica 126, 211-218. doi: 10.1023/A:1016382128401

Mandolino, G., and Ranalli, P. (2002). The applications of molecular markers in genetics and breeding of hemp. J. Ind. Hemp 7, 7-23. doi: 10.1300/ J237v07n01_03

Massimino, L. (2017). In silico gene expression profiling in Cannabis sativa. F1000Res 6:69. doi: 10.12688/f1000research.10631.1

Matsoukas, I. G. (2014). Interplay between sugar and hormone signaling pathways modulate floral signal transduction. Front. Genet. 5:218. doi: 10.3389/ fgene.2014.00218

Matsunaga, S., and Kawano, S. (2001). Sex determination by sex chromosomes in dioecious plants. Plant Biol. 3, 481-488. doi: 10.1055/s-2001-17735

Mazian, B., Bergeret, A., Benezet, J. C., and Malhautier, L. (2018). Influence of field retting duration on the biochemical, microstructural, thermal and mechanical properties of hemp fibres harvested at the beginning of flowering. Ind. Crop. Prod. 116, 170-181. doi: 10.1016/j.indcrop.2018.02.062

McCallum, C. M., Comai, L., Greene, E. A., and Henikoff, S. (2000). Targeting induced local lesions IN genomes (TILLING) for plant functional genomics. Plant Physiol. 123, 439-442. doi: 10.1104/pp.123.2.439

McGarry, R. C., and Ayre, B. G. (2012). Manipulating plant architecture with members of the CETS gene family. Plant Sci. 188, 71-81. doi: 10.1016/j. plantsci.2012.03.002

Mediavilla, V., Leupin, M., and Keller, A. (2001). Influence of the growth stage of industrial hemp on the yield formation in relation to certain fibre quality traits. Ind. Crop. Prod. 13, 49-56. doi: 10.1016/S0926-6690(00)00052-2

Melzer, S., Lens, F., Gennen, J., Vanneste, S., Rohde, A., and Beeckman, T. (2008). Flowering-time genes modulate meristem determinacy and growth form in Arabidopsis thaliana. Nat. Genet. 40, 1489-1492. doi: 10.1038/ ng. 253

Michaels, S. D., and Amasino, R. M. (1999). FLOWERING LOCUS C encodes a novel MADS domain protein that acts as a repressor of flowering. Plant Cell 11, 949-956. doi: 10.1105/tpc.11.5.949

Ming, R., Bendahmane, A., and Renner, S. S. (2011). Sex chromosomes in land plants. Annu. Rev. Plant Biol. 62, 485-514. doi: 10.1146/annurevarplant-042110-103914

Mishra, P., and Panigrahi, K. C. (2015). GIGANTEA - an emerging story. Front. Plant Sci. 6:8. doi: 10.3389/fpls.2015.00008

Mohan Ram, H. Y., and Jaiswal, V. S. (1972). Induction of male flowers on female plants of Cannabis sativa by gibberellins and its inhibition by abscisic acid. Planta 105, 263-266. doi: 10.1007/BF00385397

Moinuddin, S. G. A., Jourdes, M., Laskar, D. D., Ki, C., Cardenas, C. L., Kim, K.-W., et al. (2010). Insights into lignin primary structure and deconstruction from Arabidopsis thaliana COMT (caffeic acid O-methyl transferase) mutant Atomt1. Org. Biomol. Chem. 8, 3928-3946. doi: 10.1039/ c004817h
Moliterni, V. M. C., Cattivelli, L., Ranalli, P., and Mandolino, G. (2004). The sexual differentiation of Cannabis sativa L.: a morphological and molecular study. Euphytica 140, 95-106. doi: 10.1007/s10681-004-4758-7

Monna, L., Lin, H. X., Kojima, S., Sasaki, T., and Yano, M. (2002). Genetic dissection of a genomic region for a quantitative trait locus, Hd3, into two loci, Hd3a and Hd3b, controlling heading date in rice. Theor. Appl. Genet. 104, 772-778. doi: 10.1007/s00122-001-0813-0

Moon, J., Suh, S. S., Lee, H., Choi, K. R., Hong, C. B., Paek, N. C., et al. (2003). The SOC1 MADS-box gene integrates vernalization and gibberellin signals for flowering in Arabidopsis. Plant J. 35, 613-623. doi: 10.1046/j.1365-313X.2003.01833.x

Mutasa-Göttgens, E., and Hedden, P. (2009). Gibberellin as a factor in floral regulatory networks. J. Exp. Bot. 60, 1979-1989. doi: 10.1093/jxb/erp040

Nakajima, M., Shimada, A., Takashi, Y., Kim, Y. C., Park, S. H., Ueguchi-Tanaka, M., et al. (2006). Identification and characterization of Arabidopsis gibberellin receptors. Plant J. 46, 880-889. doi: 10.1111/j.1365-313X.2006.02748.x

Notaguchi, M., Abe, M., Kimura, T., Daimon, Y., Kobayashi, T., Yamaguchi, A., et al. (2008). Long-distance, graft-transmissible action of arabidopsis FLOWERING LOCUS T protein to promote flowering. Plant Cell Physiol. 49, 1922-1922. doi: 10.1093/pcp/pcn176

Onofri, C., and Mandolino, G. (2017). "Genomics and molecular markers in Cannabis sativa L" in Cannabis sativa L. - botany and biotechnology. eds. S. Chandra, H. Lata, and M. A. ElSohly (Cham: Springer International Publishing), 319-342.

Peil, A., Flachowsky, H., Schumann, E., and Weber, W. E. (2003). Sex-linked AFLP markers indicate a pseudoautosomal region in hemp (Cannabis sativa L.). Theor. Appl. Genet. 107, 102-109. doi: 10.1007/s00122-003-1212-5

Peng, J., Carol, P., Richards, D. E., King, K. E., Cowling, R. J., Murphy, G. P., et al. (1997). The Arabidopsis GAI gene defines a signalling pathway that negatively regulates gibberellin responses. Genes Dev. 11, 3194-3205. doi: 10.1101/gad.11.23.3194

Phillips, A. L., Ward, D. A., Uknes, S., Appleford, N. E. J., Lange, T., Huttly, A. K., et al. (1995). Isolation and expression of three gibberellin 20-oxidase cDNA clones from Arabidopsis. Plant Physiol. 108, 1049-1057. doi: 10.1104/ pp.108.3.1049

Ponnu, J., Wahl, V., and Schmid, M. (2011). Trehalose-6-phosphate: connecting plant metabolism and development. Front. Plant Sci. 2:70. doi: 10.3389/ fpls.2011.00070

Preston, J. C., and Hileman, L. C. (2013). Functional evolution in the plant SQUAMOSA-PROMOTER BINDING PROTEIN-LIKE (SPL) gene family. Front. Plant Sci. 4:80. doi: 10.3389/fpls.2013.00080

Ramanna, M. S. (1976). Are there heteromorphic sex-chromosomes in spinach (Spinacia oleracea L). Euphytica 25, 277-284. doi: 10.1007/BF00041557

Ranocha, P., Denance, N., Vanholme, R., Freydier, A., Martinez, Y., Hoffmann, L., et al. (2010). Walls are thin 1 (WAT1), an Arabidopsis homolog of Medicago truncatula NODULIN21, is a tonoplast-localized protein required for secondary wall formation in fibers. Plant J. 63, 469-483. doi: 10.1111/j.1365-313X.2010.04256.x

Razumova, O. V., Alexandrov, O. S., Divashuk, M. G., Sukhorada, T. I., and Karlov, G. I. (2016). Molecular cytogenetic analysis of monoecious hemp (Cannabis sativa L.) cultivars reveals its karyotype variations and sex chromosomes constitution. Protoplasma 253, 895-901. doi: 10.1007/ s00709-015-0851-0

Rieu, I., Eriksson, S., Powers, S. J., Gong, F., Griffiths, J., Woolley, L., et al. (2008b). Genetic analysis reveals that C19-GA 2-oxidation is a major gibberellin inactivation pathway in Arabidopsis. Plant Cell 20, 2420-2436. doi: 10.1105/ tpc. 108.058818

Rieu, I., Ruiz-Rivero, O., Fernandez-Garcia, N., Griffiths, J., Powers, S. J., Gong, F., et al. (2008a). The gibberellin biosynthetic genes AtGA20ox1 and AtGA20ox2 act, partially redundantly, to promote growth and development throughout the Arabidopsis life cycle. Plant J. 53, 488-504. doi: 10.1111/j. 1365-313X.2007.03356.x

Ruelens, P., de Maagd, R. A., Proost, S., Theissen, G., Geuten, K., and Kaufmann, K. (2013). FLOWERING LOCUS C in monocots and the tandem origin of angiosperm-specific MADS-box genes. Nat. Commun. 4:2280. doi: 10.1038/ Ncomms 3280

Ryu, C. H., Lee, S., Cho, L. H., Kim, S. L., Lee, Y. S., Choi, S. C., et al. (2009). OsMADS50 and OsMADS56 function antagonistically in regulating 
long day (LD)-dependent flowering in rice. Plant Cell Environ. 32, 1412-1427. doi: $10.1111 /$ j.1365-3040.2009.02008.x

Salentijn, E. M. J., Pereira, A., Angenent, G. C., van der Linden, C. G., Krens, F., Smulders, M. J. M., et al. (2007). Plant translational genomics: from model species to crops. Mol. Breed. 20, 1-13. doi: 10.1007/ s11032-006-9069-3

Salentijn, E. M. J., Zhang, Q. Y., Amaducci, S., Yang, M., and Trindade, L. M. (2015). New developments in fiber hemp (Cannabis sativa L.) breeding. Ind. Crop. Prod. 68, 32-41. doi: 10.1016/j.indcrop.2014.08.011

Samanfar, B., Molnar, S. J., Charette, M., Schoenrock, A., Dehne, F., Golshani, A., et al. (2017). Mapping and identification of a potential candidate gene for a novel maturity locus, E10, in soybean. Theor. Appl. Genet. 130, 377-390. doi: 10.1007/s00122-016-2819-7

Sánchez-Retuerta, C., Suarez-Lopez, P., and Henriques, R. (2018). Under a new light: regulation of light-dependent pathways by non-coding RNAs. Front. Plant Sci. 9:962. doi: 10.3389/fpls.2018.00962

Sawler, J., Stout, J. M., Gardner, K. M., Hudson, D., Vidmar, J., Butler, L., et al. (2015). The genetic structure of marijuana and hemp. PLoS One 10:e0133292. doi: 10.1371/journal.pone.0133292

Schindele, P., Wolter, F., and Puchta, H. (2018). Transforming plant biology and breeding with CRISPR/Cas9, Cas12 and Cas13. FEBS Lett. 592, 1954-1967. doi: $10.1002 / 1873-3468.13073$

Schneider, K., Kienow, L., Schmelzer, E., Colby, T., Bartsch, M., Miersch, O., et al. (2005). A new type of peroxisomal acyl-coenzyme A synthetase from Arabidopsis thaliana has the catalytic capacity to activate biosynthetic precursors of jasmonic acid. J. Biol. Chem. 280, 13962-13972. doi: 10.1074/jbc.M413578200

Shabir, G., Aslam, K., Khan, A. R., Shahid, M., Manzoor, H., Noreen, S., et al. (2017). Rice molecular markers and genetic mapping: current status and prospects. J. Integr. Agric. 16, 1879-1891. doi: 10.1016/S2095-3119(16)61591-5

Shen, Y. S., Xiang, Y., Xu, E. S., Ge, X. H., and Li, Z. Y. (2018). Major colocalized QTL for plant height, branch initiation height, stem diameter, and flowering time in an alien introgression derived brassica napus DH population. Front. Plant Sci. 9:390. doi: 10.3389/fpls.2018.00390

Shim, J. S., and Imaizumi, T. (2015). Circadian clock and photoperiodic response in Arabidopsis: from seasonal flowering to redox homeostasis. Biochemistry 54, 157-170. doi: 10.1021/bi500922q

Small, E. (2015). Evolution and classification of Cannabis sativa (Marijuana, Hemp) in relation to human utilization. Bot. Rev. 81, 189-294. doi: 10.1007/ s12229-015-9157-3

Smith, H. (2000). Phytochromes and light signal perception by plants - an emerging synthesis. Nature 407, 585-591. doi: 10.1038/35036500

Struik, P. C., Amaducci, S., Bullard, M. J., Stutterheim, N. C., Venturi, G., and Cromack, H. T. H. (2000). Agronomy of fibre hemp (Cannabis sativa L.) in Europe. Ind. Crop. Prod. 11, 107-118. doi: 10.1016/S0926-6690(99)00048-5

Tang, K., Struik, P. C., Yin, X., Thouminot, C., Bjelkova, M., Stramkale, V., et al. (2016). Comparing hemp (Cannabis sativa L.) cultivars for dualpurpose production under contrasting environments. Ind. Crop. Prod. 87, 33-44. doi: 10.1016/j.indcrop.2016.04.026

Thomas, S. G., Phillips, A. L., and Hedden, P. (1999). Molecular cloning and functional expression of gibberellin 2-oxidases, multifunctional enzymes involved in gibberellin deactivation. Proc. Natl. Acad. Sci. USA 96, 4698-4703.

Ueguchi-Tanaka, M., Ashikari, M., Nakajima, M., Itoh, H., Katoh, E., Kobayashi, M., et al. (2005). GIBBERELLIN INSENSITIVE DWARF1 encodes a soluble receptor for gibberellin. Nature 437, 693-698. doi: 10.1038/nature04028

Valverde, F., Mouradov, A., Soppe, W., Ravenscroft, D., Samach, A., and Coupland, G. (2004). Photoreceptor regulation of CONSTANS protein in photoperiodic flowering. Science 303, 1003-1006. doi: 10.1126/science.1091761

Van Bakel, H., Stout, J. M., Cote, A. G., Tallon, C. M., Sharpe, A. G., Hughes, T. R., et al. (2011). The draft genome and transcriptome of Cannabis sativa. Genome Biol. 12:R102. doi: 10.1186/Gb-2011-12-10-R102

Van den Broeck, H. C., Chris Maliepaard, C., Ebskamp, M. J. M., Toonen, M. A. J., and Koops, A. J. (2008). Differential expression of genes involved in C1 metabolism and lignin biosynthesis in wooden core and bast tissues of fibre hemp (Cannabis sativa L.). Plant Sci. 174, 205-220. doi: 10.1016/j. plantsci.2007.11.008

Van der Werf, H. M. G. (2004). Life Cycle Analysis of field production of fibre hemp, the effect of production practices on environmental impacts. Euphytica 140, 13-23. doi: 10.1007/s10681-004-4750-2
Van der Werf, H. M. G., Mathijssen, E. W. J. M., and Haverkort, A. J. (1996). The potential of hemp (Cannabis sativa $\mathrm{L}$ ) for sustainable fibre production: a crop physiological appraisal. Ann. Appl. Biol. 129, 109-123. doi: 10.1111/ j.1744-7348.1996.tb05736.x

Vanous, A., Gardner, C., Blanco, M., Martin-Schwarze, A., Lipka, A. E., Flint-Garcia, S., et al. (2018). Association Mapping of Flowering and Height Traits in Germplasm Enhancement of Maize Doubled Haploid (GEM-DH) Lines. Plant Genome 11:170083. doi: 10.3835/plantgenome2017.09.0083

Wang, B., Zhu, L., Zhao, B., Zhao, Y., Xie, Y., Zheng, Z., et al. (2019). Development of a Haploid-Inducer Mediated Genome Editing System for Accelerating Maize Breeding. Mol. Plant. 12, 597-602. doi: 10.1016/j.molp.2019.03.006

Watanabe, S., Hideshima, R., Xia, Z., Tsubokura, Y., Sato, S., Nakamoto, Y., et al. (2009). Map-based cloning of the gene associated with the soybean maturity locus E3. Genetics 182, 1251-1262. doi: 10.1534/genetics.108.098772

Watanabe, S., Xia, Z., Hideshima, R., Tsubokura, Y., Sato, S., Yamanaka, N., et al. (2011). A map-based cloning strategy employing a residual heterozygous line reveals that the GIGANTEA gene is involved in soybean maturity and flowering. Genetics 188, 395-407. doi: 10.1534/genetics.110.125062

Wenden, B., Kozma-Bognar, L., Edwards, K. D., Hall, A. J., Locke, J. C., and Millar, A. J. (2011). Light inputs shape the Arabidopsis circadian system. Plant J. 66, 480-491. doi: 10.1111/j.1365-313X.2011.04505.x

Wenkel, S., Turck, F., Singer, K., Gissot, L., Le Gourrierec, J., Samach, A., et al. (2006). CONSTANS and the CCAAT box binding complex share a functionally important domain and interact to regulate flowering of Arabidopsis. Plant Cell 18, 2971-2984. doi: 10.1105/tpc.106.043299

West, N. W., and Golenberg, E. M. (2018). Gender-specific expression of GIBBERELLIC ACID INSENSITIVE is critical for unisexual organ initiation in dioecious Spinacia oleracea. New Phytol. 217, 1322-1334. doi: 10.1111/nph.14919

Westergaard, M. (1958). The mechanism of sex determination in dioecious flowering plants. Adv. Genet. 9, 217-281.

Wigge, P. A. (2011). FT, a mobile developmental signal in plants. Curr. Biol. 21, R374-R378. doi: 10.1016/j.cub.2011.03.038

Wong, A. C., Hecht, V. F., Picard, K., Diwadkar, P., Laurie, R. E., Wen, J., et al. (2014). Isolation and functional analysis of CONSTANS-LIKE genes suggests that a central role for CONSTANS in flowering time control is not evolutionarily conserved in Medicago truncatula. Front. Plant Sci. 5:486. doi: $10.3389 /$ fpls.2014.00486

Wu, G., Park, M. Y., Conway, S. R., Wang, J. W., Weigel, D., and Poethig, R. S. (2009). The sequential action of miR156 and miR172 regulates developmental timing in Arabidopsis. Cell 138, 750-759. doi: 10.1016/j.cell.2009.06.031

Xia, Z., Watanabe, S., Yamada, T., Tsubokura, Y., Nakashima, H., Zhai, H., et al. (2012). Positional cloning and characterization reveal the molecular basis for soybean maturity locus E1 that regulates photoperiodic flowering. Proc. Natl. Acad. Sci. USA 109, E2155-E2164. doi: 10.1007/s00122-016-2819-7

Xu, X., Paik, I., Zhu, L., and Huq, E. (2015). Illuminating progress in phytochromemediated light signaling pathways. Trends Plant Sci. 20, 641-650. doi: 10.1016/j.tplants.2015.06.010

Xue, W., Xing, Y., Weng, X., Zhao, Y., Tang, W., Wang, L., et al. (2008). Natural variation in Ghd7 is an important regulator of heading date and yield potential in rice. Nat. Genet. 40, 761-767. doi: 10.1038/ng.143

Yamamoto, K., Oda, Y., Haseda, A., Fujito, S., Mikami, T., and Onodera, Y. (2014). Molecular evidence that the genes for dioecism and monoecism in Spinacia oleracea L. are located at different loci in a chromosomal region. Heredity 112, 317-324. doi: 10.1038/hdy.2013.112

Yano, M., Kojima, S., Takahashi, Y., Lin, H. X., and Sasaki, T. (2001). Genetic control of flowering time in rice, a short-day plant. Plant Physiol. 127, 1425-1429. doi: 10.1104/pp.010710

Zeng, X., Liu, H., Du, H., Wang, S., Yang, W., Chi, Y., et al. (2018). Soybean MADS-box gene GmAGL1 promotes flowering via the photoperiod pathway. BMC Genomics 19:51. doi: 10.1186/s12864-017-4402-2

Zhai, H., Lu, S., Wu, H., Zhang, Y., Zhang, X., Yang, J., et al. (2015). Diurnal expression pattern, allelic variation, and association analysis reveal functional features of the E1 gene in control of photoperiodic flowering in soybean. PLoS One 10:e0135909. doi: 10.1371/journal.pone.0135909

Zhang, J., Zhou, X., Yan, W., Zhang, Z., Lu, L., Han, Z., et al. (2015). Combinations of the Ghd7, Ghd8 and Hd1 genes largely define the ecogeographical adaptation and yield potential of cultivated rice. New Phytol. 208, 1056-1066. doi: $10.1111 / \mathrm{nph} .13538$ 
Zhao, Q., and Dixon, R. A. (2011). Transcriptional networks for lignin biosynthesis: more complex than we thought? Trends Plant Sci. 16, 227-233. doi: 10.1016/j. tplants.2010.12.005

Zhao, Q., Nakashima, J., Chen, F., Yin, Y., Fu, C., Yun, J., et al. (2013). Laccase is necessary and nonredundant with peroxidase for lignin polymerization during vascular development in Arabidopsis. Plant Cell 25, 3976-3987. doi: 10.1105/tpc.113.117770

Zhao, C., Takeshima, R., Zhu, J., Xu, M., Sato, M., Watanabe, S., et al. (2016). A recessive allele for delayed flowering at the soybean maturity locus E9 is a leaky allele of FT2a, a FLOWERING LOCUS T ortholog. BMC Plant Biol. 16:20. doi: 10.1186/s12870-016-0704-9
Conflict of Interest Statement: The authors declare that the research was conducted in the absence of any commercial or financial relationships that could be construed as a potential conflict of interest.

Copyright (c) 2019 Salentijn, Petit and Trindade. This is an open-access article distributed under the terms of the Creative Commons Attribution License (CC $B Y)$. The use, distribution or reproduction in other forums is permitted, provided the original author(s) and the copyright owner(s) are credited and that the original publication in this journal is cited, in accordance with accepted academic practice. No use, distribution or reproduction is permitted which does not comply with these terms. 